\title{
Superthreshold Behavior and Threshold Estimation of Ultrasound-Induced Lung Hemorrhage in Adult Mice and Rats
}

\author{
James F. Zachary, Jason M. Sempsrott, Leon A. Frizzell, Senior Member, IEEE, \\ Douglas G. Simpson, and William D. O'Brien, Jr., Fellow, IEEE
}

\begin{abstract}
Threshold estimates and superthreshold behaviors for ultrasound-induced lung hemorrhage were investigated as a function of species (adult mice and rats) and ultrasound frequency (2.8 and 5.6 MHz). A total of 151 6-to7-week-old female ICR mice and 160 10-to-11-week-old female Sprague-Dawley rats were randomly divided into two ultrasonic frequency groups, and further randomly divided into seven or eight ultrasonic peak rarefactional pressure groups. Each group consisted of about 10 animals. Animals were exposed to pulsed ultrasound at either $2.8 \mathrm{-MHz}$ center frequency (1-kHz PRF, 1.42- $\mu$ s pulse duration) or $5.6-\mathrm{MHz}$ center frequency (1-kHz PRF, $1.17-\mu$ s pulse duration) for a duration of 10 seconds. The in situ (at the pleural surface) peak rarefactional pressure levels ranged between 2.5 and 10.5 MPa for mice and between 2.3 and 11.3 MPa for rats. The mechanical index (MI) ranged between 1.4 and 6.3 at 2.8 $\mathrm{MHz}$ for mice and between 1.1 and 3.1 at $5.6 \mathrm{MHz}$ for rats. The lesion surface area and depth were measured for each animal as well as the percentage of animals with lesions per group. The characteristics of the lesions produced in mice and rats were similar to those described in previous studies by our research group and others, suggesting a common pathogenesis in the initiation and propagation of the lesions at the gross and microscopic levels. The percentage of animals with lesions showed no statistical differences between species or between ultrasound frequencies. These findings suggest that mice and rats are similar in sensitivity to ultrasound-induced lung damage and that the occurrence of lung damage is independent of frequency. Lesion depth and surface area also showed no statistically significant differences between ultrasound frequencies for mice and rats. However, there was a significant difference between species for lesion area and a suggestive difference between species for lesion depth. The superthreshold behavior of lesion area and depth showed that rat lung had more damage than mouse lung, and the threshold estimates showed a weak, or lack of, frequency dependency, suggesting that the MI is not consistent with the observed findings.
\end{abstract}

Manuscript received March 17, 2000; accepted September 21, 2000. This work was supported by NIH Grant HL58218 awarded to W. D. O'Brien, Jr. and J. F. Zachary and NSF Grant DMS-0073044 awarded to D. G. Simpson.

J. F. Zachary is with the Department of Veterinary Pathobiology, University of Illinois, Urbana, IL 61802 (e-mail: zacharyj@staff.uiuc.edu).

J. M. Sempsrott, L. A. Frizzell, and W. D. O'Brien, Jr. are with the Bioacoustics Research Laboratory, Department of Electrical and Computer Engineering, University of Illinois, Urbana, IL 61801.

D. G. Simpson is with the Department of Statistics, University of Illinois, Champaign, IL 61820.

\section{INTRODUCTION}

$T$ HE safety record of clinical use of diagnostic ultrasound has been remarkable, with no reported adverse effects in humans. However, concerns for its safety have been raised following the publication of experimental findings documenting lung hemorrhage in mice [1]-[9], rats [10]-[12], rabbits [6], [8], monkeys [13], and pigs [14], [15] at levels of ultrasound exposure and pulsing conditions consistent with those used for ultrasonography in humans. Several studies have indicated that heating is not responsible for ultrasound-induced lung hemorrhage [1], [2], [16]. One recent study [17] demonstrated that lung hemorrhage is not produced by inertial cavitation. Other mechanical effects (noncavitational mechanisms) can occur in the presence of larger gas bodies within tissues (such as air in lung alveoli) or in tissues lacking cavitation nuclei. Such effects include radiation force, radiation torque, and microstreaming, any of which can cause tissue injury through stress and shearing phenomena [18].

This article reports the results of two experiments that directly compare the incidence (percentage with lesions) and size (lesion surface area and depth) of ultrasoundinduced lung hemorrhage in mice and rats exposed at center frequencies of 2.8 and $5.6 \mathrm{MHz}$ using the same exposure system and conditions. Such direct comparisons have not been made in the past. Rather, generalized trends of damage threshold as a function of species and frequency have been deduced from an evaluation of separate experiments [18]. Understanding species dependency will provide valuable insight into whether (and how) the mechanism of lung damage in animals can be extrapolated to humans. Understanding frequency dependency will provide knowledge related to the pathogenesis of ultrasound-induced lung hemorrhage and a scientific basis for reviewing the applicability of the output display standard's mechanical index [19], [20].

\section{Materials AND Methods}

\section{A. Exposimetry}

Ultrasonic exposures were conducted using two focused, 19-mm-diameter, lithium niobate ultrasonic transducers (Valpey Fisher, Hopkinton, MA). Water-based (distilled 
TABLE I

Water-Based Pulse-Echo Ultrasonic Field Distribution Results for the Two 19-mm-Diameter Lithium Niobate Ultrasonic Transducers.

\begin{tabular}{lcc}
\hline Pulse-echo quantity & Transducer 1 & Transducer 2 \\
\hline Center frequency (MHz) & 2.8 & 5.6 \\
Fractional bandwidth $(\%)$ & 11.6 & 12.5 \\
Focal length $(\mathrm{mm})$ & 18.9 & 37.4 \\
-6-dB focal beamwidth $(\mu \mathrm{m})$ & 466 & 448 \\
-6-dB depth of focus $(\mathrm{mm})$ & 2.73 & 6.87 \\
\hline
\end{tabular}

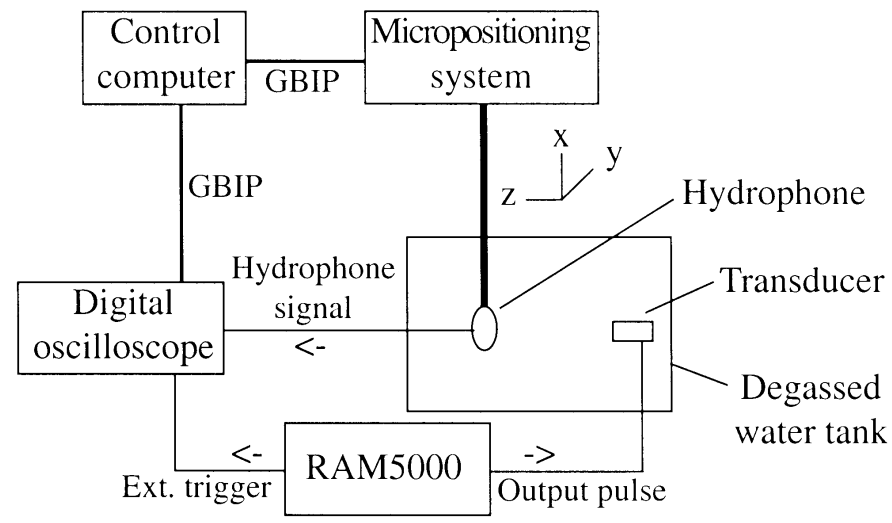

Fig. 1. Block diagram of ultrasound calibration procedure.

water, $22^{\circ} \mathrm{C}$ ) pulse-echo ultrasonic field distribution measurements were performed according to established procedures [21]-[23] (Table I).

An automated procedure was developed to routinely calibrate the ultrasound fields [20]-[23]. The procedure was based on the AIUM standards [24] and the output display standard [19]. The source transducer's drive voltage was supplied by a RAM5000 (Ritec, Inc., Warwick, RI) that had the capability to deliver up to a $5-\mathrm{kW}$ single-cycle pulse into a 50-ohm load (Fig. 1). To simplify the automated procedure, the source transducer was manually positioned in a water tank (degassed water, $22^{\circ} \mathrm{C}$ ) such that its beam axis was approximately parallel to the z-axis. Either of two calibrated PVDF membrane hydrophones (Perceptron Model 804-010, Plymouth Meeting, PA, and Marconi Model Y-34-6543, Chelmsford, UK) was mounted to the computer-controlled micropositioning system (Daedal, Inc., Harrisburg, PA). Each of the three orthogonal axes of the micropositioning system had a linear accuracy of $2 \mu \mathrm{m}$. The hydrophone's signal was digitized with an oscilloscope $(500 \mathrm{Ms} / \mathrm{s}$, LeCroy Model 9354TM, Chestnut Ridge, NY), the output of which was fed to the same computer (Dell Pentium II, Round Rock, TX) that controlled the positioning system.

The pulse intensity integral (PII) was the basic field quantity used to estimate the beam axis:

$$
\mathrm{PII}=\frac{1}{\rho \mathrm{c}} \int_{\mathrm{t}_{1}}^{\mathrm{t}_{2}}(\mathrm{p}(\mathrm{t}))^{2} \mathrm{dt}
$$

where $\rho \mathrm{c}$ was the characteristic acoustic impedance of water, $\mathrm{p}(\mathrm{t})$ was the instantaneous acoustic pressure determined from the calibrated hydrophone, and the limits of integration completely bracketed the duration of the pulse. The PII was calculated for each pulse by the same computer that controlled the micropositioning system and acquired the digitized hydrophone voltage.

The source transducer's beam axis was estimated by determining the straight line that consisted of points of the maximum PII at several distances from the transducer. Maximum PII values were determined in five separate $x-y$ planes (Fig. 1), with adjacent planes separated by $2 \mathrm{~mm}$. These $x-y$ planes were approximately perpendicular to the beam axis and spanned axially (z direction) the focal region. Manual control of the micropositioning system was used to find the focus' location; the focus was defined as the location at which the hydrophone's RF signal on the oscilloscope was a maximum. The hydrophone's starting position (i.e., the origin for the automated procedure) was located $500 \mu \mathrm{m}$ laterally in both the $\mathrm{x}$ - and $\mathrm{y}$-directions, and $2 \mathrm{~mm}$ toward the transducer from the focus in the $\mathrm{z}$-direction. The hydrophone was scanned in $50-\mu \mathrm{m}$ increments over a distance of $1 \mathrm{~mm}$ in the $\mathrm{x}$-direction to locate the maximum PII along that line, then returned to the origin. The process was repeated in the y-direction. Assuming a circular symmetric field about the beam axis, these two maximum PII values determined the axial maximum PII in the first $x-y$ plane. This process was repeated in four additional planes, each separated by $2 \mathrm{~mm}$ in the z-direction, away from the transducer. A total of five maximum PII values resulted, one for each $\mathrm{x}-\mathrm{y}$ plane. A linear regression analysis used the coordinates of these five maximum PII values to determine an equation of the beam axis. Calculations for this phase of the calibrations were conducted by the control computer.

The control computer used the beam axis equation to position the hydrophone along the beam axis. Beginning at the first $x-y$ plane, the system acquired RF hydrophone waveforms at $50-\mu \mathrm{m}$ intervals along the beam axis. The acquisition rate was $500 \mathrm{Ms} / \mathrm{s}$. For both the $2.8-\mathrm{MHz}$ and $5.6-\mathrm{MHz}$ source transducers, the axial range over which the $\mathrm{RF}$ waveforms were acquired was $8 \mathrm{~mm}$. The only exception to the calibration procedure as discussed above was the insertion of a 13-ohm in-line attenuator between the RAM5000 and transducer; this configuration was used for sham exposures to yield a very low exposure level during transducer alignment procedures (see below). The RF data were transferred to a Sun UltraSparc workstation and analyzed using Matlab ${ }^{\circledR}$ (The Mathworks, Natick, MA).

The RF hydrophone waveforms were processed to yield axial profiles for the following quantities: rarefactional pressure, compressional pressure, pulse intensity integral, and their derated $(0.3 \mathrm{~dB} / \mathrm{cm}-\mathrm{MHz})$ values. Typical axial profiles of these quantities are shown in Fig. 2 at both frequencies for both a lower and a higher output.

The maximum water-based value of the rarefactional pressure axial profile is termed the peak rarefactional pressure and denoted as $\operatorname{p}_{r(i n}$ vitro). The maximum water-based 

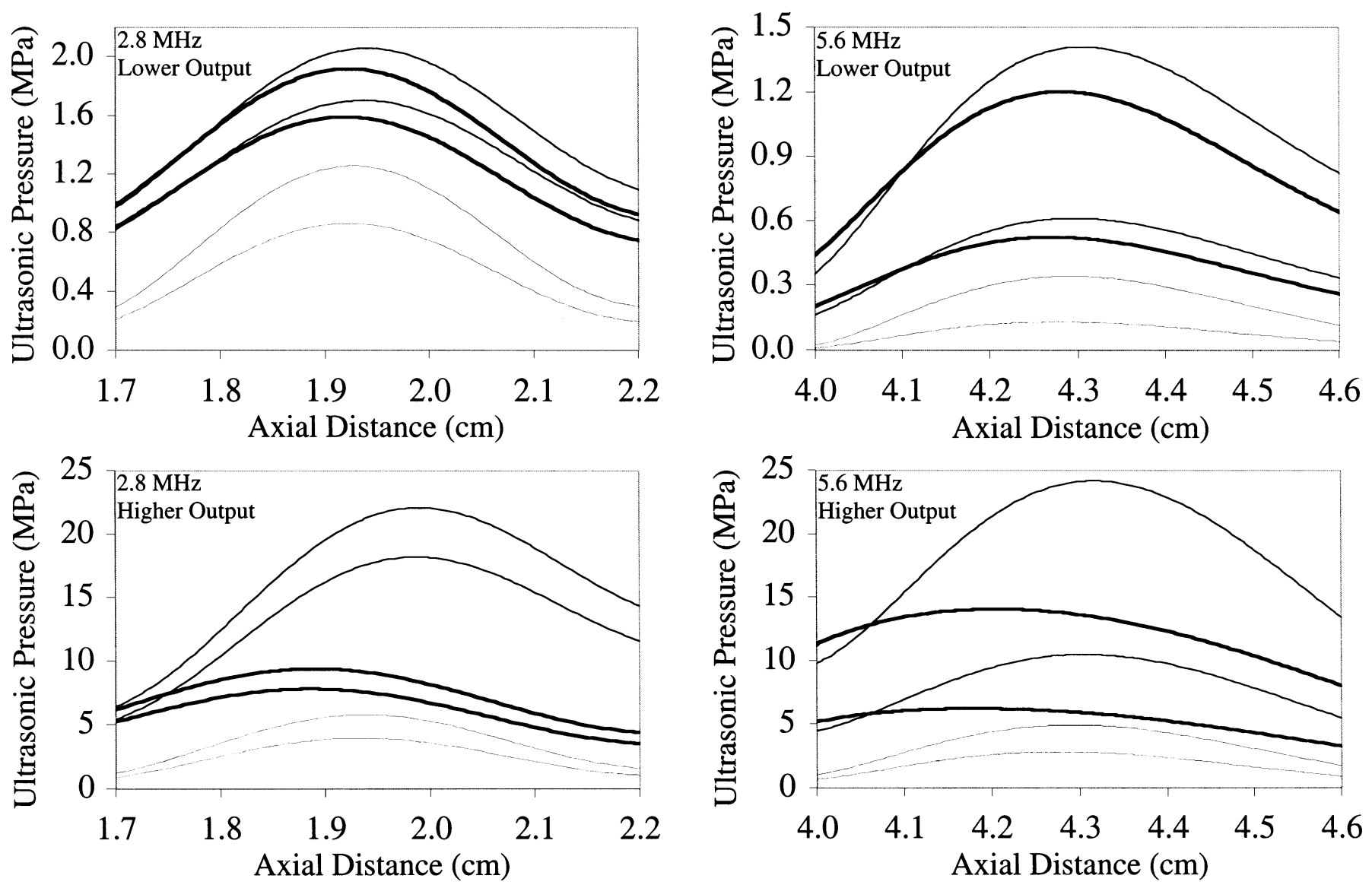

Fig. 2. Four examples of the axial distribution for peak ultrasonic pressures (top four lines in each panel) and the relative pulse intensity integral (bottom two lines in each panel). The two left panels are the field values for the $2.8-\mathrm{MHz}$ transducer, and the two right panels are the field values for the 5.6-MHz transducer. The two top panels are lower-output conditions, and the two bottom panels are higher-output conditions. The bold ultrasonic pressure lines in each panel are the peak rarefactional pressure; the higher-valued line is the water value, and the lower-valued line is the $0.3 \mathrm{~dB} / \mathrm{cm}-\mathrm{MHz}$ derated value. The ultrasonic pressure lines (lighter lines) in each panel are the peak compressional pressure; the higher-valued line is the water value, and the lower-valued line is the $0.3 \mathrm{~dB} / \mathrm{cm}-\mathrm{MHz}$ derated value. The two thin bottom lines in each panel are the relative pulse intensity integral; the higher-valued line is the water value, and the lower-valued line is the $0.3 \mathrm{~dB} / \mathrm{cm}-\mathrm{MHz}$ derated value.

value of the compressional pressure axial profile is termed the peak compressional pressure and denoted as $\mathrm{p}_{\mathrm{c} \text { (in vitro) }}$. The maximum water-based value of the pulse intensity integral axial profile is termed the peak pulse intensity integral and denoted as $\mathrm{PII}_{\text {(in vitro) }}$. The $0.3 \mathrm{~dB} / \mathrm{cm}-\mathrm{MHz}$ derated values of the two peak pressure quantities, determined from the derated axial profiles, are denoted as $p_{\text {r.3 }}$ and $\mathrm{p}_{\mathrm{c} .3}$, respectively, and were determined at the location of the maximum value of the derated pulse intensity integral $\mathrm{PII}_{3}$. The MI was calculated using the ODS procedure [19] from $p_{\text {r.3 }} / \sqrt{f_{c}}$, where $f_{c}$ is the center frequency of either 2.8 or $5.6 \mathrm{MHz}$ (Table II). It is worth noting (as discussed below) our purpose for providing the MI in Table II. The ultrasound-induced lung damage reported herein is probably not related quantitatively to the MI. The MI is a regulated quantity [20] of diagnostic ultrasound systems, and its value is available to system operators. Thus, there is value to provide the MI for each of our exposure settings in order to give general guidance to manufacturers and operators as to the levels we are using in this study. Further, it is a quantity that cannot be determined if we only report $\operatorname{p}_{r \text { (in vitro) }}$ (see below), the exposure quantity we are using to report our findings.

Twenty-two independent calibrations of the $2.8-\mathrm{MHz}$ transducer and 19 independent calibrations of the $5.6-\mathrm{MHz}$ transducer were conducted before, during, and after the 5 -month period of the experiments. Standard deviations of $\operatorname{pr}_{r \text { (in vitro) }}$ were less than $17 \%$ of their respective mean values for the $2.8 \mathrm{-MHz}$ transducer and $16 \%$ for the 5.6 $\mathrm{MHz}$ transducer. Standard deviations of $\mathrm{p}_{\mathrm{c} \text { (in vitro) were }}$ less than $21 \%$ of their respective mean values for the 2.8 $\mathrm{MHz}$ transducer and $19 \%$ for the $5.6-\mathrm{MHz}$ transducer. The measured pulse durations [24] were 1.42 and $1.14 \mu \mathrm{s}$ at the center frequencies of 2.8 and $5.6 \mathrm{MHz}$, respectively.

The in situ (at the pleural surface) peak rarefactional and compressional pressures were estimated from:

$$
\operatorname{pr}_{r(i n \text { situ })}=\operatorname{pr}_{r(\text { in vitro })} \mathrm{e}^{-(\mathrm{A} \cdot \mathrm{x})}
$$

and

$$
\mathrm{p}_{\mathrm{c}(\text { in situ })}=\mathrm{p}_{\mathrm{c}(\text { in vitro })} \mathrm{e}^{-(\mathrm{A} \cdot \mathrm{x})},
$$

respectively, where $\mathrm{p}_{\mathrm{r}(\mathrm{in} \text { vitro) }}$ and $\mathrm{p}_{\mathrm{c}(\mathrm{in} \text { vitro) }}$ are the max- 
TABLE II

Mean Values of the In Situ (at the Pleural Surface) Peak Rarefactional Pressure Pr(in situ) and Peak Compressional Pressure $\left.\mathrm{P}_{\mathrm{C}(\mathrm{IN}} \mathrm{Situ}\right){ }^{1}$

\begin{tabular}{|c|c|c|c|c|c|c|}
\hline $\begin{array}{l}\text { Number of } \\
\text { animals }\end{array}$ & $\begin{array}{l}\operatorname{p}_{\operatorname{r}(\text { in situ })} \\
\quad(\mathrm{MPa})\end{array}$ & $\begin{array}{c}\mathrm{p}_{\mathrm{c}(\mathrm{in} \mathrm{situ})} \\
(\mathrm{MPa})\end{array}$ & MI & $\%$ lesions & $\begin{array}{l}\text { Mean }(\mathrm{SE}) \\
\text { lesion area } \\
\quad\left(\mathrm{mm}^{2}\right)\end{array}$ & $\begin{array}{l}\text { Mean (SE) } \\
\text { lesion depth } \\
\quad(\mathrm{mm})\end{array}$ \\
\hline \multicolumn{7}{|c|}{ Mice at $2.8 \mathrm{MHz}$} \\
\hline 15 (sham) & 0.28 & 0.30 & 0.15 & 0 & - & - \\
\hline 10 & 2.49 & 3.15 & 1.41 & 10 & $0.03(0.03)$ & $0.02(0.02)$ \\
\hline 10 & 3.66 & 4.02 & 2.02 & 0 & - & - \\
\hline 10 & 4.83 & 5.54 & 2.62 & 20 & $0.91(0.70)$ & $0.24(0.21)$ \\
\hline 10 & 6.00 & 6.49 & 3.23 & 20 & $0.30(0.20)$ & $0.15(0.11)$ \\
\hline 10 & 7.17 & 7.67 & 3.84 & 30 & $0.31(0.21)$ & $0.10(0.08)$ \\
\hline 10 & 8.33 & 9.91 & 4.44 & 50 & $0.47(0.24)$ & $0.21(0.11)$ \\
\hline 10 & 9.50 & 11.8 & 5.05 & 60 & $1.70(0.75)$ & $0.45(0.18)$ \\
\hline 10 & 10.7 & 13.7 & 5.66 & 80 & $5.96(2.42)$ & $0.87(0.22)$ \\
\hline \multicolumn{7}{|c|}{ Mice at $5.6 \mathrm{MHz}$} \\
\hline 15 (sham) & 0.27 & 0.30 & 0.06 & 0 & - & - \\
\hline 10 & 4.72 & 8.34 & 1.13 & 10 & $0.03(0.03)$ & $0.03(0.03)$ \\
\hline 10 & 5.81 & 10.4 & 1.38 & 20 & $0.32(0.25)$ & $0.09(0.07)$ \\
\hline 10 & 6.89 & 13.2 & 1.64 & 30 & $0.19(0.12)$ & $0.93(0.82)$ \\
\hline 10 & 7.71 & 15.9 & 1.84 & 50 & $1.23(0.64)$ & $0.27(0.13)$ \\
\hline 10 & 8.53 & 17.3 & 2.03 & 70 & $1.12(0.32)$ & $1.09(0.65)$ \\
\hline 11 & 9.34 & 18.3 & 2.22 & 82 & $2.63(0.59)$ & $0.80(0.16)$ \\
\hline 10 & 10.2 & 18.6 & 2.41 & 80 & $1.77(0.45)$ & $0.55(0.11)$ \\
\hline \multicolumn{7}{|c|}{ Rats at $2.8 \mathrm{MHz}$} \\
\hline 10 (sham) & 0.26 & 0.28 & 0.15 & 0 & - & - \\
\hline 10 & 2.34 & 2.96 & 1.41 & 0 & - & - \\
\hline 10 & 4.53 & 5.20 & 2.62 & 10 & $0.09(0.09)$ & $0.08(0.08)$ \\
\hline 11 & 6.72 & 7.20 & 3.84 & 64 & $1.40(0.41)$ & $0.58(0.15)$ \\
\hline 9 & 7.82 & 9.30 & 4.44 & 78 & $2.23(0.65)$ & $0.64(0.15)$ \\
\hline 10 & 8.92 & 11.1 & 5.05 & 70 & $2.02(0.53)$ & $0.71(0.18)$ \\
\hline 10 & 10.0 & 12.9 & 5.66 & 80 & $3.32(0.68)$ & $0.89(0.16)$ \\
\hline 10 & 11.1 & 16.8 & 6.26 & 80 & $6.55(1.28)$ & $1.32(0.24)$ \\
\hline \multicolumn{7}{|c|}{ Rats at $5.6 \mathrm{MHz}$} \\
\hline 10 (sham) & 0.23 & 0.26 & 0.06 & 0 & - & - \\
\hline 10 & 3.17 & 4.20 & 0.87 & 0 & - & - \\
\hline 10 & 4.12 & 7.29 & 1.13 & 10 & $0.67(0.67)$ & $0.079(0.08)$ \\
\hline 11 & 5.07 & 9.07 & 1.38 & 18 & $0.09(0.07)$ & $0.08(0.06)$ \\
\hline 9 & 6.03 & 11.6 & 1.64 & 22 & $0.25(0.17)$ & $0.33(0.24)$ \\
\hline 10 & 6.98 & 14.3 & 1.90 & 40 & $0.75(0.46)$ & $0.26(0.13)$ \\
\hline 10 & 7.93 & 15.7 & 2.16 & 70 & $1.80(0.67)$ & $0.73(0.22)$ \\
\hline 10 & 8.88 & 16.2 & 2.41 & 60 & $2.21(0.71)$ & $0.87(0.29)$ \\
\hline 10 & 10.1 & 17.4 & 2.74 & 80 & $2.36(0.57)$ & $0.99(0.18)$ \\
\hline 10 & 11.3 & 18.1 & 3.06 & 100 & $6.48(1.36)$ & $1.59(0.09)$ \\
\hline
\end{tabular}

\footnotetext{
${ }^{1}$ All animals were exposed to pulsed ultrasound (pulse repetition frequency of $1 \mathrm{kHz}$ and exposure duration of $10 \mathrm{~s}$ ). The sham exposure conditions used a pulse repetition frequency of $10 \mathrm{~Hz}$. Mean values of the mechanical index (MI) are provided because the MI is a regulated quantity of diagnostic ultrasound equipment.
}

imum water-based values, $\mathrm{A}$ is the mean attenuation coefficient of the chest wall's intercostal tissue $(2.8 \mathrm{~dB} / \mathrm{cm}$ at $2.8 \mathrm{MHz} ; 5.9 \mathrm{~dB} / \mathrm{cm}$ at $5.6 \mathrm{MHz}$ ) measured from 41 separate mouse chest walls and 27 separate rat chest walls using a broadband insertion loss technique [25], and $\mathrm{x}$ is the mean chest wall thickness (151 mice: $3.06 \pm 0.71 \mathrm{~mm}$; 160 rats: $5.04 \pm 0.46 \mathrm{~mm}$ ).

The experimental findings are analyzed and reported in terms of the in situ (at the pleural surface) peak rarefactional pressure $\operatorname{pr}_{\mathrm{r} \text { (in situ) }}$ (Table II).

\section{B. Animals}

The experimental protocol was approved by the campus' Laboratory Animal Care Advisory Committee and satisfied all campus and NIH rules for the humane use of laboratory animals. Animals were housed in an AAALACapproved animal facility, placed in groups of three or four in polycarbonate cages with beta-chip bedding and wire bar lids, and provided food and water ad libitum.

In the first experiment, a total of 151 6-to-7-weekold 27.8 \pm 2.1-gram female ICR mice (Harlan Sprague Dawley Laboratories, Indianapolis, IN) were divided into two ultrasonic frequency groups $(2.8$ and $5.6 \mathrm{MHz})$. The 
ultrasonic frequency groups were subdivided into eight $(2.8 \mathrm{MHz})$ and seven $(5.6 \mathrm{MHz})$ ultrasonic pressure groups consisting of 10 or 11 mice in each group. In the second experiment, a total of 160 10-to-11-week-old 255 \pm 34 -gram female Sprague-Dawley rats were divided into two ultrasonic frequency groups (2.8 and 5.6 MHz). The ultrasonic frequency groups were subdivided into nine $(2.8 \mathrm{MHz})$ and seven $(5.6 \mathrm{MHz})$ ultrasonic pressure groups consisting of 9,10 , or 11 rats in each group (Table II). The exposures were conducted in four separate groupings of frequency and species. For example, all of the $2.8-\mathrm{MHz}$ mice were done at the same time. For each of the four groupings, animals were assigned to an ultrasonic pressure group at random. Sham exposures were incorporated into the randomization in each of the groupings (Table II). The individuals involved in animal handling, exposure, and lesion scoring were blinded to the exposure condition (i.e., the ultrasonic pressure level). The exposure condition for each animal was revealed only after the final results were tabulated.

Mice and rats were weighed then anesthetized with ketamine hydrochloride $(87.0 \mathrm{mg} / \mathrm{kg})$ and xylazine $(13.0 \mathrm{mg} / \mathrm{kg})$ administered intraperitoneally. For each animal, the skin of the left thorax was exposed by removing the hair with an electric clipper, followed by a depilatory agent (Nair ${ }^{\circledR}$ Carter-Wallace, Inc., New York, NY) to maximize sound transmission. A black dot was placed on the skin over the ribs at approximately the sixth to ninth rib to guide the positioning of the ultrasonic beam. Anesthetized animals were placed in specially designed holders that were sized for each species. The ultrasonic transducer was attached to the holder. A removable pointer, attached to the transducer, was used to position the ultrasonic beam perpendicular to the skin at the position of the black dot with the beam's focal region approximately at the lung surface (Fig. 3). The ultrasonic beam was incident on the lateral surface of the lung.

The holder with the animal and mounted transducer was placed in degassed, temperature-controlled $\left(30^{\circ} \mathrm{C}\right)$ water. The low-power pulse-echo capability of the exposure system (RAM5000) displayed on an oscilloscope was used to adjust the axial center of the focal region to within $1 \mathrm{~mm}$ of the lung surface. It was during this part of the experimental procedure that the 13-ohm in-line attenuator was placed between the RAM5000 and transducer to obtain very low exposure values (see sham in Table II for these low-level ultrasonic pressure levels). Also, the pulse repetition frequency was $10 \mathrm{~Hz}$ during this alignment procedure. The ultrasound propagation media between the transducer and the animal's skin surface was degassed water as also was used for transducer calibrations. Animals were exposed to pulsed ultrasound with a pulse repetition frequency of $1 \mathrm{kHz}$ and an exposure duration of $10 \mathrm{~s}$. Following exposure, animals (mice and rats) were removed from the water and holder, then euthanized under anesthesia by cervical dislocation.

The left thoracic wall was opened and the thickness of the intercostal tissue (skin, fat, fascia, muscle, and parietal pleura) between the ribs was measured with a digital micrometer (accuracy: $10 \mu \mathrm{m}$ ) at the black dot used for transducer alignment. These chest wall measurements were used for later calculation of the in situ ultrasonic pressures at the visceral pleural surface. The lungs were removed from each animal and the left lung lobe was scored for the presence or absence of hemorrhage. Lung hemorrhage formed along the pathway of the ultrasound beam, and the lesion assumed a conical shape. The base of the lesion originated at the visceral pleural surface and was elliptical in shape. The lesion extended into lung parenchyma to form its apex at varied depths within the lung (Fig. 4). The left lung was fixed by immersion in 10\% neutral-buffered formalin for a minimum of 24 hours. After fixation, the elliptical dimensions of each lung lesion at the visceral pleural surface were measured using a digital micrometer where " $\mathrm{a}$ " is the semi-major axis and "b" is the semi-minor axis. The lesion was then bisected and the depth "d" of the lesion within the pulmonary parenchyma also was measured. The surface area $(\pi \mathrm{ab})$ and volume $(\pi \mathrm{abd} / 3)$ of the lesion were calculated for each animal. Each half of the bisected lesion was embedded in paraffin, sectioned at $5 \mu \mathrm{m}$, stained with hematoxylin and eosin, and evaluated microscopically.

\section{Statistics}

Logistic regression analysis was used to examine the dependence of the probability of inducing a lesion on the species, frequency, and peak rarefactional pressure. As described in standard texts such as [26], the logistic regression model expresses the log-odds of an event as a linear regression model with coefficients for each of the variables in the study. The modeling and analysis of statistical significance was performed using S-Plus ${ }^{\circledR}$ (MathSoft Inc., Cambridge, MA). Logistic regression estimates and confidence intervals were transformed to yield estimates and confidence intervals for the ED05 threshold, i.e., the in situ peak rarefactional pressure that leads to a $5 \%$ probability of a lesion [27]. The ED05 estimates and standard errors were computed using CatReg, a categorical regression module for S-Plus ${ }^{\circledR}[28]$.

Depth and root surface area (surface area was squareroot transformed, that is, [surface area] ${ }^{0.5}$ ) of lesions were analyzed with linear regression analysis using S-Plus ${ }^{\circledR}$. Animals exhibiting no lesions were included as zero values in the analysis. Residual plots and Cook's D influence statistics [29] were examined to identify outliers and to develop a sensitivity analysis to determine whether outliers substantially affect the conclusions. Graphs of ordered residuals versus normal percentiles indicated the need for a square root transformation of surface area in order to achieve an adequate fit of a linear model. After transformation, no outliers or influential points were detected for the surface area model. Two observations were flagged as outliers for the depth model: a mouse in the $5.6-\mathrm{MHz} / 6.89$ MPa group had a lesion $8.33 \mathrm{~mm}$ deep but only $0.09 \mathrm{~mm}^{2}$ in surface area; and a mouse in the $5.6-\mathrm{MHz} / 8.53-\mathrm{MPa}$ group had a lesion $6.85 \mathrm{~mm}$ deep but only $0.26 \mathrm{~mm}^{2}$ in sur- 

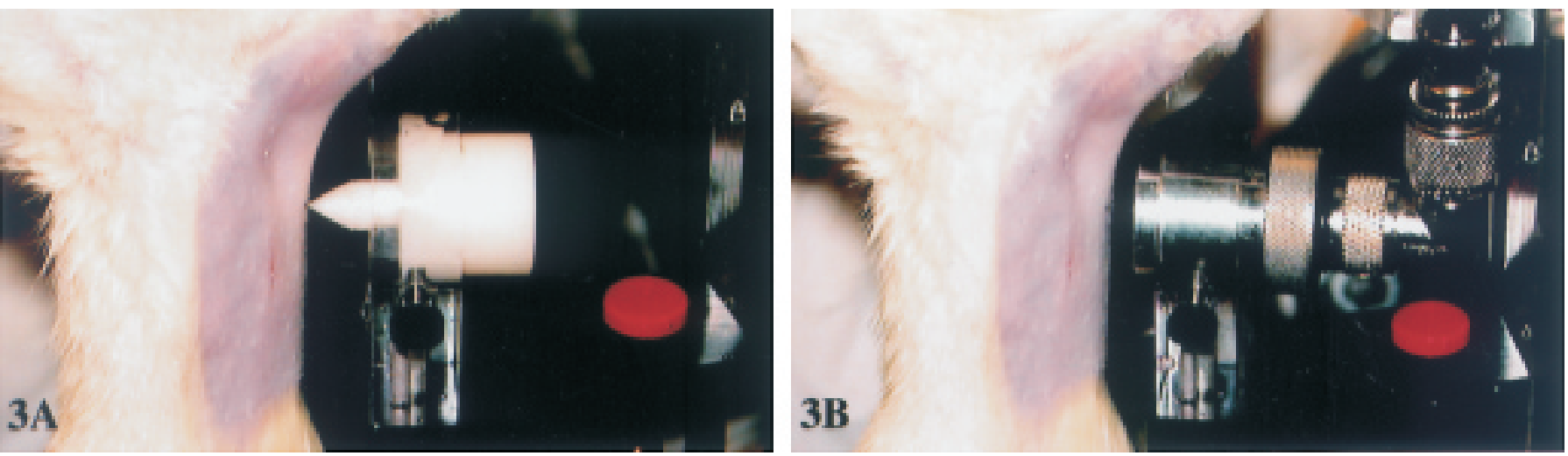

Fig. 3. Apparatus used to hold, position, and align the transducer's field on the left lung of the experimental animal. (A) A removable pointer, placed in the transducer holder, is used to position the ultrasonic beam perpendicular to the skin in the beam's focal region (see black dot at tip of pointer on depilated skin). (B) The pointer is replaced with the transducer prior to each exposure (see black dot on depilated skin where the ultrasonic beam is focused).
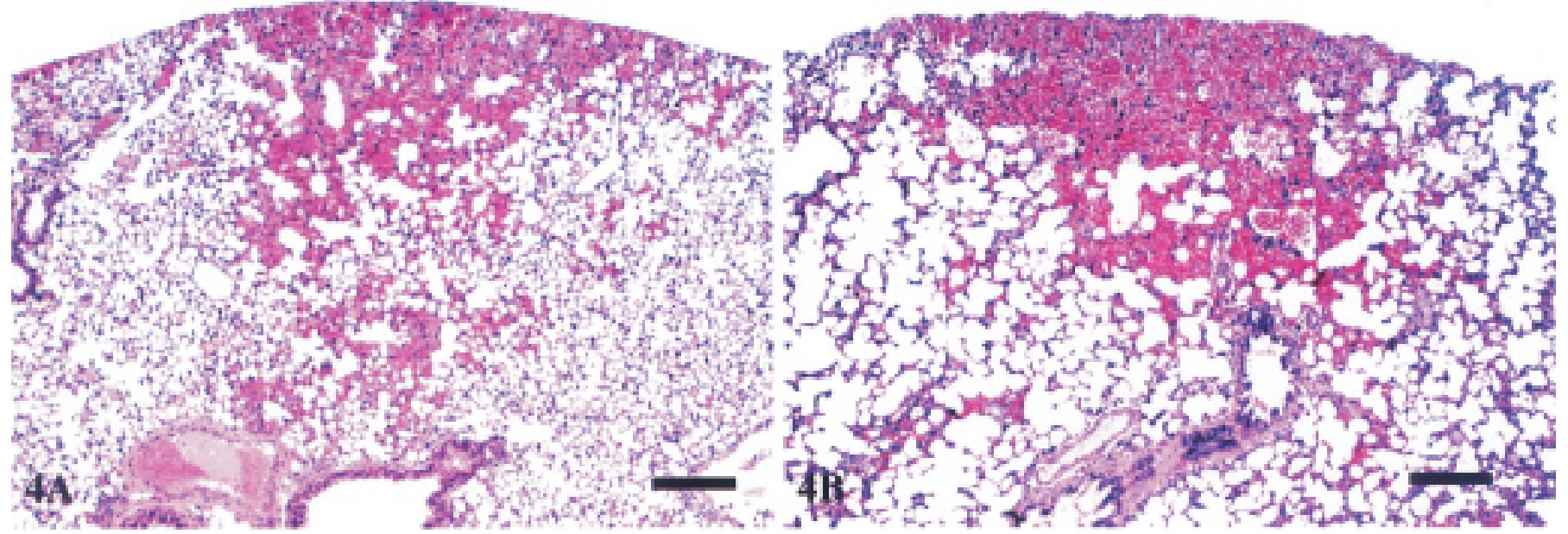

Fig. 4. Microscopically, the area of hemorrhage has a conical shape. The base of the lesion opposes the visceral pleural surface, and the apex extends into subjacent lung parenchyma. (A) Mouse. (B) Rat. Bar $=200 \mu \mathrm{m}$.

face area. The regression model for depth was fit with and without these observations to determine their influence on the conclusions of the statistical analysis. Zero crossings of the fitted regression lines along with their standard errors were computed in S-Plus ${ }^{\circledR}$ using matrix calculations. Standard errors were derived by first-order Taylor. The zero crossings indicate in situ peak rarefactional pressures for which the expected lesion size is close to zero.

\section{RESUlTS}

\section{A. Gross and Histological Observations}

Grossly, the lesion visible on the visceral pleura surface was a red to dark red elliptical area of hemorrhage that formed along the pathway of the ultrasound beam (Fig. 5). Examination of the bisected lesion demonstrated hemorrhage that assumed a conical shape whose base opposed the visceral pleural surface and whose apex extended into subjacent lung parenchyma. Microscopically, the lesion was alveolar hemorrhage; alveolar septa did not ap- pear injured. The principle tissue affected was the microvasculature. There were no differences in the gross or microscopic characteristics of the lesion based on species exposed or ultrasonic frequencies used except, for those characteristics (surface area, depth) determined by exposure condition (peak rarefactional pressure).

\section{B. Percentage of Animals with Lesions}

The logistic regression model-including effects for species, frequency, and in situ peak rarefactional pressure - was highly statistically significant, with a loglikelihood ratio chi-square of 121.6 on 3 degrees of freedom, so the trends observed in the percentage of animals with lesions could not be explained by chance alone (mice: $\mathrm{N}=151$; rats: $\mathrm{N}=160$ ) (Fig. 6). The Z-tests for the individual coefficients in the model indicated that in situ peak rarefactional pressure was highly statistically significant $(\mathrm{p}<0.0001)$, whereas species $(\mathrm{p}=0.17)$ and frequency $(\mathrm{p}=0.88)$ were not significant. The fitted model gave the estimated in situ peak rarefactional pressure ED05 values 


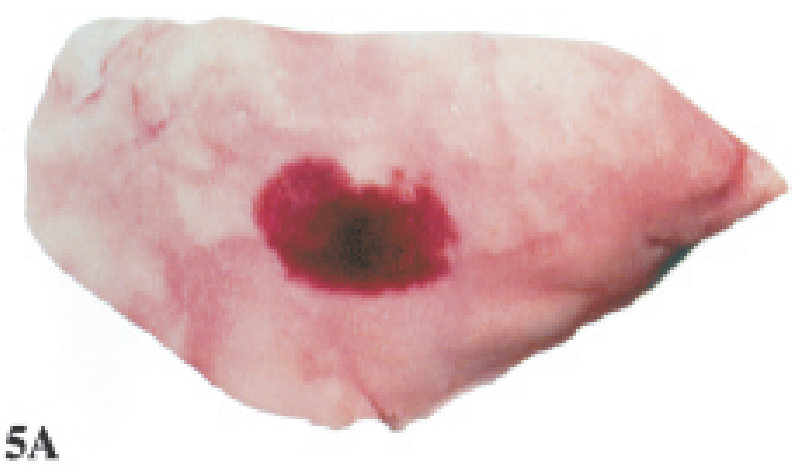

\section{A}

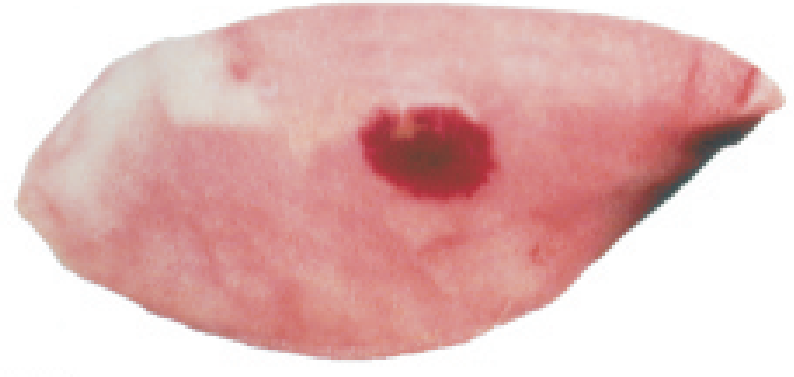

5B
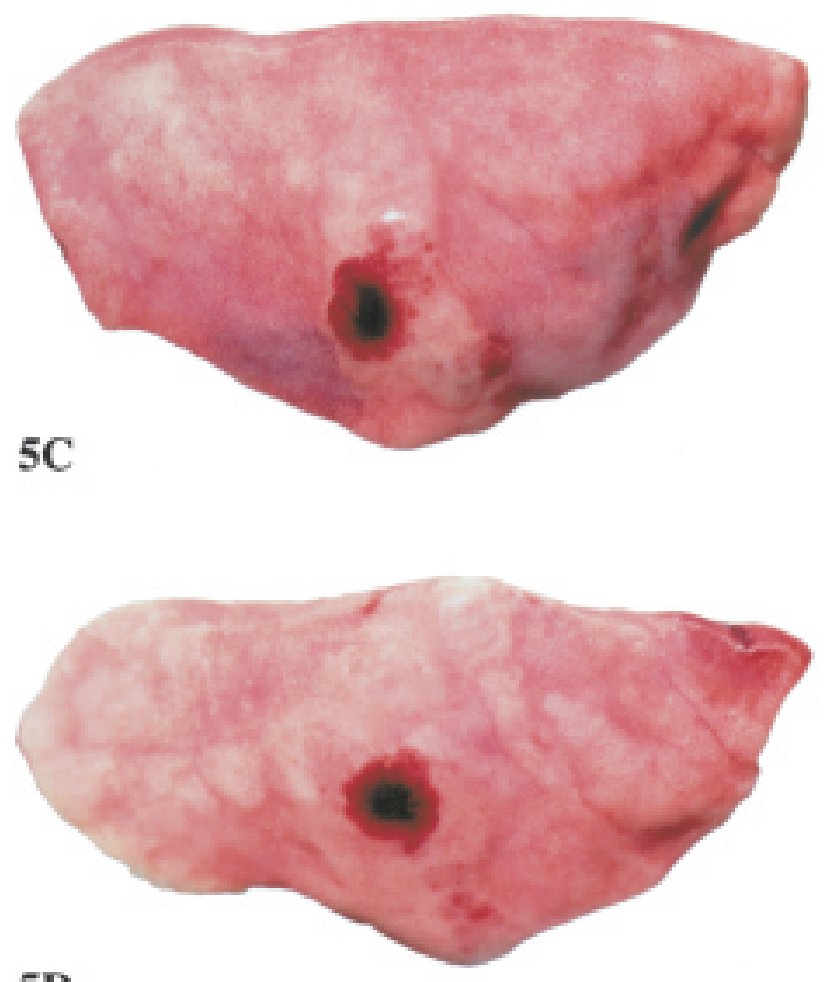

5D
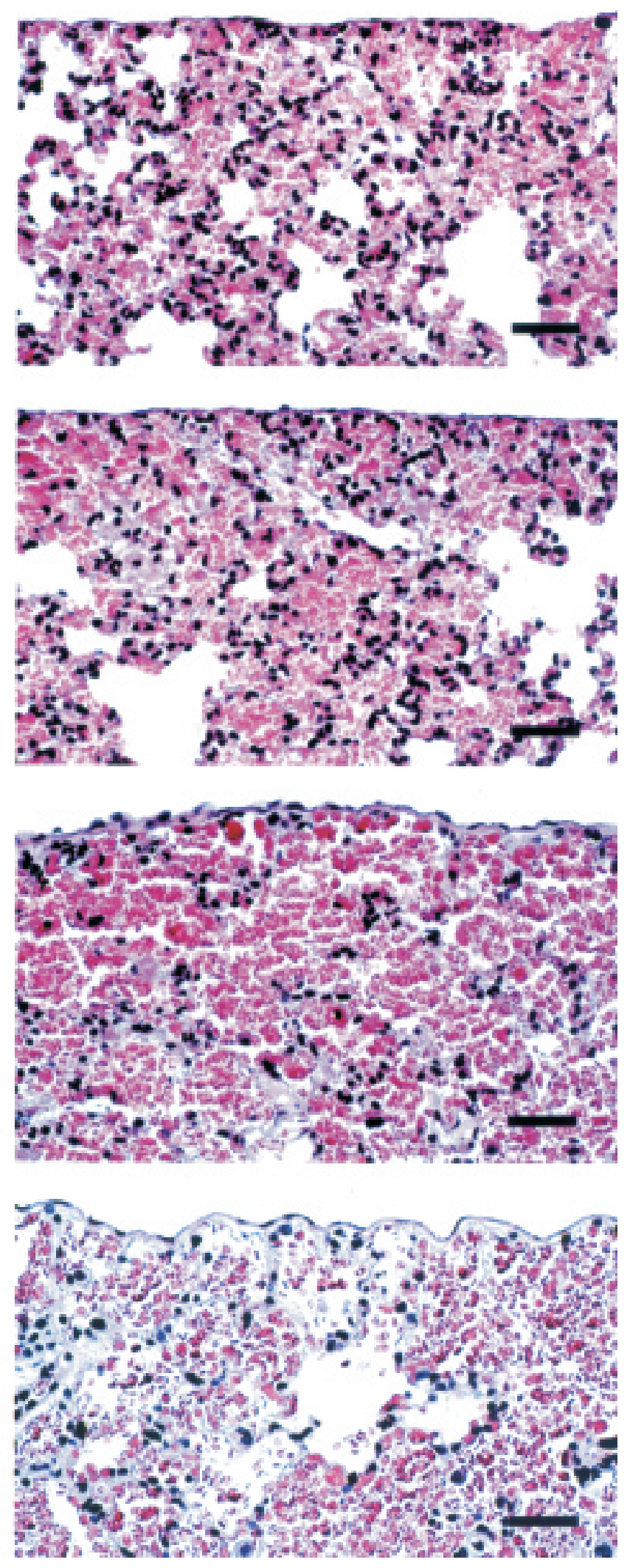

Fig. 5. Grossly (left panel), the lesion on the surface of the lung is a red to dark red expansile elliptical area of hemorrhage. The visceral pleura is intact. Histologically (right panel), the lesion is alveolar hemorrhage; alveolar septa do not appear injured. Lesions are similar in character in both mice and rats, but they vary in severity based on exposure conditions. (A) Mouse: $\mathrm{f}=2.8 \mathrm{MHz}$; $\mathrm{p}_{\mathrm{r}(\mathrm{in} \text { situ) }}=10.7 \mathrm{MPa}$; lesion area $=5.11 \mathrm{~mm}^{2}$, depth $=1.03 \mathrm{~mm}$, volume $=1.74 \mathrm{~mm}^{3}$. (B) Mouse: $\mathrm{f}=5.6 \mathrm{MHz} ; \mathrm{p}_{\mathrm{r}(\mathrm{in} \mathrm{situ})}=9.34 \mathrm{MPa}$; lesion area $=3.77 \mathrm{~mm}{ }^{2}$, depth $=1.42 \mathrm{~mm}$, volume $=1.78 \mathrm{~mm}^{3}$. (C) Rat: $\mathrm{f}=2.8 \mathrm{MHz} ; \mathrm{p}_{\mathrm{r} \text { (in situ) }}=15.5 \mathrm{MPa}$; lesion area $=7.41 \mathrm{~mm}^{2}$, depth $=1.10 \mathrm{~mm}$, volume $=2.74 \mathrm{~mm}^{3}$. (D) Rat: $\mathrm{f}=5.6 \mathrm{MHz} ; \mathrm{p}_{\mathrm{r} \text { (in situ })}=11.3 \mathrm{MPa}$; lesion area $=9.78 \mathrm{~mm}^{2}$, depth $=1.82 \mathrm{~mm}$, volume $=5.93 \mathrm{~mm}{ }^{3}$. Bar $=40 \mu \mathrm{m}$. 


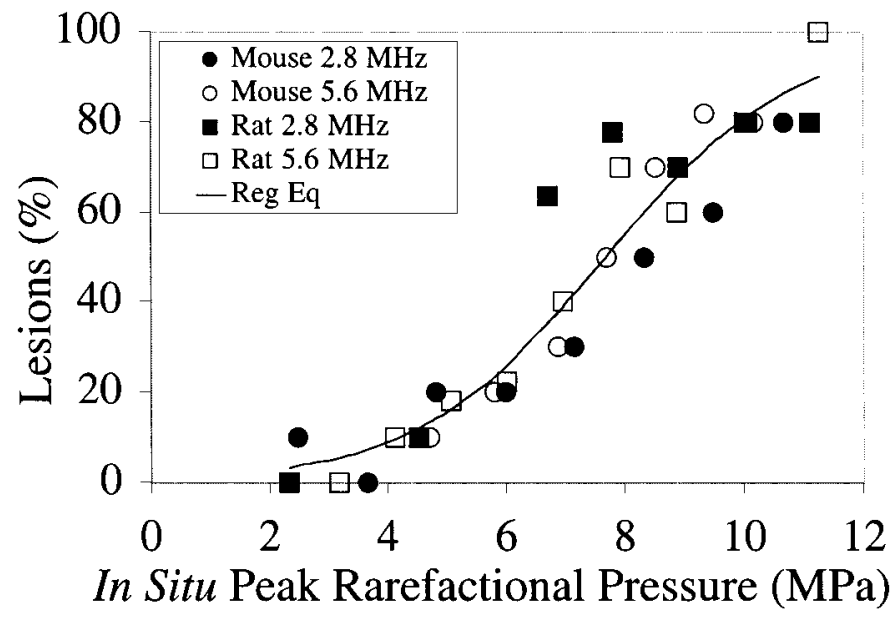

Fig. 6. Percentage of lesions as a function of the in situ peak rarefactional pressure for all data (mice: $\mathrm{N}=151$; rats: $\mathrm{N}=160$ ). The solid line is the logistic regression equation.

and standard errors (Table III). The $95 \%$ confidence intervals for the ED05 are overlapped, reflecting the lack of significance of the species and frequency differences. Removing species and frequency from the model led to a combined estimated odds ratio of 1.87 , a near doubling of the odds of a lesion, for each $1 \mathrm{MPa}$ increase in peak rarefactional pressure. The combined ED05 threshold was estimated to occur at an in situ peak rarefactional pressure of $3.0( \pm 0.6) \mathrm{MPa}$. A combined $95 \%$ confidence interval for the threshold ranged from 0.7 to $4.1 \mathrm{MHz}$.

\section{Lesion Surface Area and Depth}

The linear regression of root surface area with coefficients for species, frequency, and in situ peak rarefactional pressure was highly significant with an $\mathrm{R}^{2}$ of 0.40 (mice: $\mathrm{N}=147$; rats: $\mathrm{N}=160$ ) (Fig. 7). Based on t-tests for the individual coefficients in the model, the species difference in surface area was significant $(\mathrm{p}=0.001)$, the difference due to frequency was suggestive but not significant $(\mathrm{p}=0.09)$, and the in situ peak rarefactional pressure was highly significant $(\mathrm{p}<0.0001)$. The fitted model gave the estimated in situ peak rarefactional pressure zero-crossing values and standard errors (Table III).

The linear regression model for lesion depth was fit with and without two outliers. With the outliers (mice: N=147; rats: $\mathrm{N}=160$ ) (Fig. 7 ), the model, although highly significant, exhibited an $\mathrm{R}^{2}$ of only 0.20 . The difference in depth due to species was approaching significance $(p=0.064)$, whereas the difference due to frequency was not significant $(p=0.49)$. In situ peak rarefactional pressure was a highly significant regressor $(\mathrm{p}<0.0001)$. Without the outliers (mice: $\mathrm{N}=145$; rats: $\mathrm{N}=160$ ), $\mathrm{R}^{2}$ increased to 0.39 , which is consistent with the fit of the regression model for root surface area. Evidently the outliers accounted for a substantial portion of the residual error. With outliers removed, both the species effect and the in situ peak rarefactional pressure were highly significant $(\mathrm{p}<0.0001)$, and frequency was not significant $(\mathrm{p}=0.46)$. The fitted model
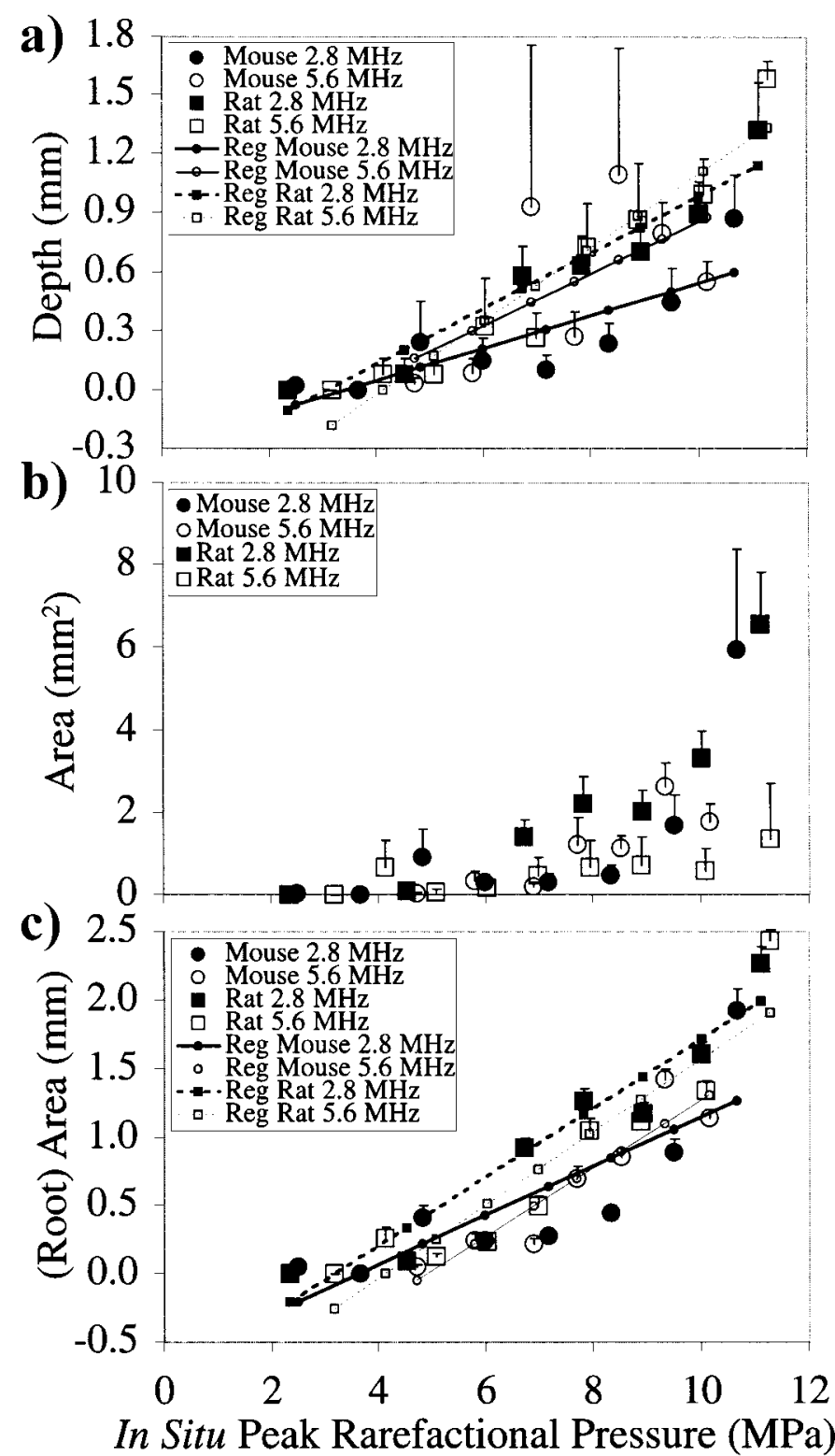

Fig. 7. Mean lesion (a) depth, (b) area, and (c) root area as a function of the in situ peak rarefactional pressure for all data (mice: $\mathrm{N}=151$; rats: $\mathrm{N}=160$ ). The one-way error bars are the standard errors of the mean (SEM). The linear regression lines are shown for depth (a) and root area (c), the two quantities for which statistical evaluations were conducted.

gave the estimated in situ peak rarefactional pressure zerocrossing values and standard errors for both with and without outliers (Table III). The outlier measurements occurred for two of the mice in the study. These outliers affected both the mouse and the rat estimates of zerocrossings, because the final model includes only a single coefficient for MPa rather than species by MPa interaction. However, the differences between estimated zero-crossings for rats with and without the outliers are within sampling variation. Without the outliers, all of the estimated zerocrossings are consistent with the estimated zero-crossings for surface area. 
TABLE III

Estimated In Situ Peak Rarefaction Pressure Thresholds for Mice and Rats at 2.8 and 5.6 MHz for Lesion Occurrence, Area, and Depth Using the Indicated Methodology.

\begin{tabular}{lclcc}
\hline & & & \multicolumn{2}{c}{ Threshold estimate $^{1}(\mathrm{MPa})$} \\
\cline { 3 - 5 } Species & $\begin{array}{c}\text { Frequency } \\
(\mathrm{MHz})\end{array}$ & Measure & $\begin{array}{c}\text { ED05 } \\
\text { (standard error) }\end{array}$ & $\begin{array}{c}\text { Zero crossing } \\
\text { (standard error })\end{array}$ \\
\hline Mouse & 2.8 & Occurrence & $3.6( \pm 0.7)$ & \\
Mouse & 2.8 & Area & & $4.2( \pm 0.4)$ \\
Mouse & 2.8 & Depth (outliers included) & & $4.5( \pm 0.6)$ \\
Mouse & 2.8 & Depth (outliers excluded) & & \\
Mouse & 5.6 & Occurrence & $3.0( \pm 0.7)$ & $4.9( \pm 0.4)$ \\
Mouse & 5.6 & Area & & $4.0( \pm 0.7)$ \\
Mouse & 5.6 & Depth (outliers included) & & \\
Mouse & 5.6 & Depth (outliers excluded) & & $3.0( \pm 0.4)$ \\
Rat & 2.8 & Occurrence & & $3.2( \pm 0.7)$ \\
Rat & 2.8 & Area & & $2.8( \pm 0.5)$ \\
Rat & 2.8 & Depth (outliers included) & \\
Rat & 2.8 & Depth (outliers excluded) & $2.8( \pm 0.7)$ & $3.6( \pm 0.4)$ \\
Rat & 5.6 & Occurrence & & $2.9( \pm 0.7)$ \\
Rat & 5.6 & Area & & $3.1( \pm 0.5)$ \\
Rat & 5.6 & Depth (outliers included) & & \\
Rat & 5.6 & Depth (outliers excluded) & & \\
\hline
\end{tabular}

${ }^{1}$ ED05: Obtained by inverting the logistic regression model for the $5 \%$ probability. Zero crossing: obtained by the $\operatorname{p}_{r}($ in situ) zero crossing from the linear regression analyses.

\section{Analysis of Lesion Shape}

Lesion area and depth were correlated with a Pearson correlation coefficient of 0.51 . Root surface area and depth exhibited a correlation coefficient of 0.63 . These correlations persisted after adjustment for species, frequency, and in situ peak rarefactional pressure; the partial correlation coefficient between depth and root surface is 0.52 .

\section{Discussion}

The characteristics of the lesions produced in mice and rats from this study were similar to those described in previous studies [1], [3]-[9], [11], [12]. The lesion visible under the visceral pleura surface was a red to dark red elliptical area of centripetally expanding hemorrhage. Extension of hemorrhage into deeper lung parenchyma assumed a conical shape whose base opposed the visceral pleural surface and apex extended into subjacent lung parenchyma (Fig. 5). The long axis of the lesion was not parallel with the ribs but followed the normal axis (movement) of the chest during the respiratory cycle.

These findings suggest a common pathogenesis in the initiation and propagation of the lesions at the gross and microscopic levels. We hypothesize that the pathogenesis of ultrasound-induced lung hemorrhage is a two-step process. The first step requires "initiation" of the lesion at the tissue-air interface formed by the visceral pleura and contiguous alveoli at the site of exposure. Tissue injury results in hemorrhage that fills alveoli with blood. The nature of this injury remains to be determined. The second step requires "propagation" of the lesion into deeper tissues by spread of the acoustic energy through blood-filled alveoli to the next tissue-air interface in contiguous air-filled alveoli. It is through this repetitive process that the lesion likely forms its conical shape. The depth of the lesion may be limited by attenuation of sound energy in blood-filled alveoli as the lesion expands into deeper tissue or by loss of energy as the beam refracts from the focal point at the visceral pleural surface as it encounters deeper areas of the lung.

The elliptical shape of the lesion on the lung surface is consistent with both the beam shape and the lung movement relative to the ultrasound beam. As the threshold conditions are met, the area of the lesion may increase over a larger area of the lung surface. The penetration into the lung is consistent with the hypothesis of Raeman et al. [4] that the initial damage at the surface results in fluid filling that increases penetration of the sound into the lung such that damage results at greater depths. Thus, the hemorrhage is initiated at the lung surface, just under the visceral pleura, but propagates from the surface deeper into the lung. The elliptical shape of the lesion on the lung surface suggests that the lesion originates from a small point just under the visceral pleura and spreads out laterally and from that point into adjacent lung parenchyma. The normal movement of the lung and thoracic wall during the respiratory cycle (inspiration and expiration) contributes, in part, to the elliptical shape of the surface lesion; but it does not account for the conical shape of the deeper lesion. The conical expansion of the lesion to form the apex of the cone in deeper lung tissue implies a uniform extension of the lesion and of ultrasound energy into these lung tissues (lesion depth and [root] surface area are correlated). Both of the outlier lesions reported here exhibited an unusual 
shape in which deep lesions had relatively small surface areas. This pattern of damage might occur if an animal were completely stationary and possibly not breathing during ultrasound, because the beam target then would be highly localized. However, this hypothesis has not been tested.

No differences for either species or ultrasound frequency on the occurrence (percentage) of lesions were noted (Fig. 6). Further, no differences on frequency for both lesion depth and area were noted, although there was a difference for species on lesion area and a suggestive difference for species on lesion depth (Fig. 7). The occurrence (percentage) results are consistent with the prediction that mice and rats should be relatively similar in sensitivity to lung damage [18], although the lesion area and depth results suggest the possibility of different sensitivities for mice and rats. The superthreshold behavior of lesion area and depth, as seen from the regression equations (Fig. 7), shows that rat lung has more damage than mouse lung.

It is unclear why lesion propagation, or rate of growth, should be greater in the rat than the mouse. Examination of the literature provides no clear guidance. On one hand, this result is remarkably consistent with results of Dalecki et al. [9] in which lesion area was examined as a function of acoustic pressure amplitude for neonatal, juvenile, and adult mice. It was shown that, although the thresholds for lung hemorrhage were similar for the three age groups, the lesion area was significantly larger (increased at a far greater rate for comparable changes in acoustic pressure) in adults than in the juveniles or neonates. Thus, the larger the animal the larger the suprathreshold hemorrhage area, as found in this study comparing mice and rats. On the other hand, Baggs et al. [14] showed that the rate of growth of lesion area in 10-day-old swine, which were many times larger than adult mice, was on the same order or less than for the adult mice.

A possible explanation for the superthreshold behavior differences observed between mice and rats could relate to the fact that the ribs are more closely spaced in the mouse (approximately $3 \mathrm{~mm}$ between rib centers) than in the rat (approximately $5 \mathrm{~mm}$ between rib centers). The issue is not the size of the ribs but the width of the intercostal space between the ribs. The intercostal space between ribs becomes wider among species as they increase in body weight (e.g., rat intercostal space is wider than mouse) and as animals increase in body weight within a species as they age. Although the focused ultrasound beam is positioned in the intercostal space (between the ribs), the respiratory cycle moves the spatially fixed beam in and out of the intercostal space during exposure. Therefore, the ultrasound beam will inevitably hit the cranial and caudal ribs with each respiratory cycle. The closer the rib spacing the more likely the ultrasound beam will be intercepted by the ribs during chest wall movement with respiration. Thus, it is likely that the small differences seen in this study are not due to differing sensitivity of the lungs to pulsed ultrasound in mice and rats, but to increased shading of the ultrasound field by the mouse's ribs compared to that by the rat's ribs.

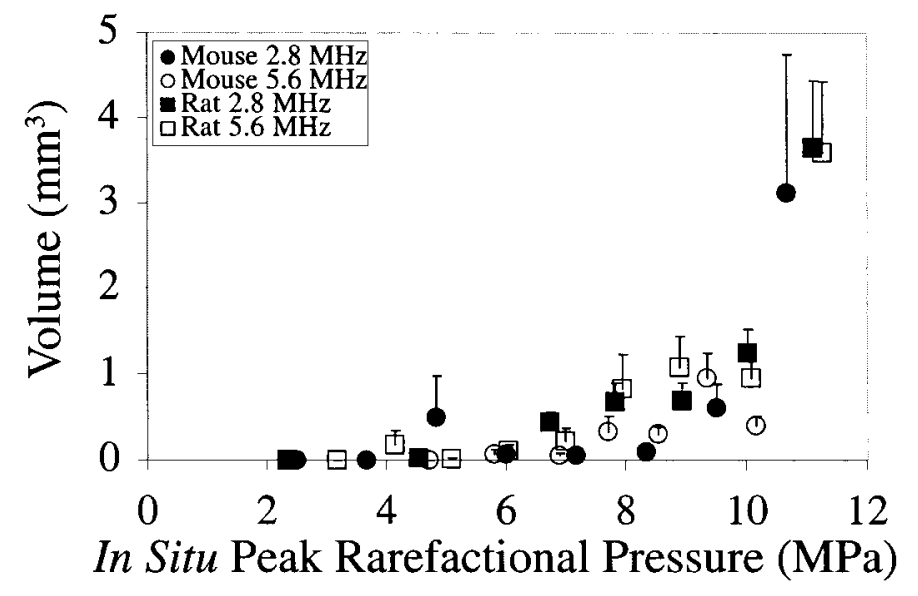

Fig. 8. Mean lesion volume as a function of the in situ peak rarefactional pressure for all data (mice: $\mathrm{N}=151$; rats: $\mathrm{N}=160$ ). The one-way error bars are the standard errors of the mean (SEM).

The region of the exposure-response curve that marks the transition from "no-lesion" to "lesion" is one definition for the threshold. However, this is an unrealistic definition in terms of determining a quantitative threshold estimate because the number of animals necessary to ver-

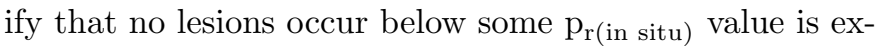
cessive. Instead, as used herein, the threshold estimates use all of the acquired data, and an extrapolation from the superthreshold exposure conditions. In situ peak rarefaction pressure threshold estimates for lesion occurrence (percentage), area, and depth for each species and frequency are listed in Table III. Lesion occurrence (percentage) threshold is based on ED05, that is the $5 \%$ occurrence based on the logistic regression model probability. The lesion area and depth thresholds are based on the linear regression $\mathrm{p}_{\mathrm{r} \text { (in situ) }}$ zero crossing as defined in the Materials and Methods section.

The minimal difference in thresholds observed between the two frequencies used in this study is of note, and perhaps quite significant. The transducer characteristics were chosen so that the focal beam diameter was very nearly the same for the two frequencies used (though the focal depth and water-based nonlinear characteristics are different). It is not obvious from lesion volume (Fig. 8) how suprathreshold lesion development depends on frequency in this study. However, examination of Table III allows us to estimate the frequency dependence in the thresh-

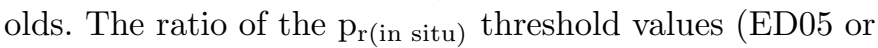
zero crossing) at $5.6 \mathrm{MHz}$ to that at $2.8 \mathrm{MHz}$ yields 0.833 and 1.22 for mouse and rat occurrence (percentage), respectively; 1.17 and 1.20 for mouse and rat surface area, respectively; 0.889 and 0.906 for mouse and rat depth with outliers, respectively; and 1.06 and 1.11 for mouse and rat depth without outliers, respectively. These values are all much smaller ratios than $1.41(\sqrt{5.6 / 2.8})$ predicted by the square root of frequency dependence in the MI. The frequency dependence built into the MI was developed specifically to reflect the best idea as to the dependence of the likelihood for cavitation on frequency under specified con- 
ditions [19]. In fact, previous results for thresholds for, and extent of, lung damage have fit the frequency dependence exhibited by the MI reasonably well [18]. This outcome was true, despite the fact that the mechanism for damage to the lung does not appear to be inertial cavitation [17].

\section{CONCLUSION}

These results suggest the need to examine further the frequency dependence for lung damage and the application of the MI to prediction of mechanical effects not associated with an inertial cavitation mechanism.

\section{ACKNOWLEDGMENTS}

We thank D. Abano, R. Bashyal, J. Blue, J. Brown, T. Bruns, J. Christoff, M. Ho, H. Luo, B. McNeill, R. Miller, K. Norrell, G. Teotico, L. Tuazon, and A. Wunderlich for technical contributions.

\section{REFERENCES}

[1] S. Z. Child, C. L. Hartman, L. A. Schery, and E. L. Carstensen, "Lung damage from exposure to pulsed ultrasound," Ultrasound Med. Biol., vol. 16, pp. 817-825, 1990.

[2] C. Hartman, S. Z. Child, R. Mayer, E. Schenk, and E. L. Carstensen, "Lung damage from exposure to the fields of an electrohydraulic lithotripter," Ultrasound Med. Biol., vol. 16, pp. 675-679, 1990.

[3] D. P. Penney, E. A. Schenk, K. Maltby, C. Hartman-Raeman, S. Z. Child, and E. L. Carstensen, "Morphologic effects of pulsed ultrasound in the lung," Ultrasound Med. Biol., vol. 19, pp. 127135, 1993.

[4] C. H. Raeman, S. Z. Child, and E. L. Carstensen, "Timing of exposures in ultrasonic hemorrhage of murine lung," Ultrasound Med. Biol., vol. 19, pp. 507-517, 1993.

[5] L. A. Frizzell, E. Chen, and C. Lee, "Effects of pulsed ultrasound on the mouse neonate: Hind limb paralysis and lung hemorrhage," Ultrasound Med. Biol., vol. 20, pp. 53-63, 1994.

[6] J. F. Zachary and W. D. O'Brien, Jr., "Lung lesion induced by continuous- and pulsed-wave (diagnostic) ultrasound in mice, rabbits, and pigs," Vet. Pathol., vol. 32, pp. 43-54, 1995.

[7] C. H. Raeman, S. Z. Child, D. Dalecki, C. Cox, and E. L. Carstensen, "Exposure-time dependence of the threshold for ultrasonically induced murine lung hemorrhage," Ultrasound Med. Biol., vol. 22, pp. 139-141, 1996.

[8] W. D. O'Brien, Jr., and J. F. Zachary, "Lung damage assessment from exposure to pulsed-wave ultrasound in the rabbit, mouse, and pig," IEEE Trans. Ultrason., Ferroelect., Freq. Contr., vol. 44, pp. 473-485, 1997.

[9] D. Dalecki, S. Z. Child, C. H. Raeman, D. P. Penney, C. Cox, D. P. Penny, and E. L. Carstensen, "Age dependence of ultrasonically induced lung hemorrhage in mice," Ultrasound Med. Biol., vol. 23, pp. 767-776, 1997.

[10] C. K. Holland, K. Sandstrom, X. Zheng, J. Rodriguey, and R. A. Roy, "The acoustic field of a pulsed Doppler diagnostic ultrasound system near a pressure-release surface," J. Acoust. Soc. Amer., vol. 95, p. 2855, 1994 (abstract).

[11] W. D. O'Brien, Jr., J. F. Zachary, D. J. Schaeffer, and L. A. Frizzell, "Superthreshold behavior of ultrasound induced lung hemorrhage in adult mice and rats: role of pulse repetition frequency and pulse duration," to be published.

[12] C. K. Holland, C. X. Deng, R. E. Apfel, J. L. Alderman, L. A. Ferandez, and K. J. W. Taylor, "Direct evidence of cavitation in vivo from diagnostic ultrasound," Ultrasound Med. Biol., vol. 22, pp. 917-925, 1996.
[13] A. F. Tarantal and D. R. Canfield, "Ultrasound-induced lung hemorrhage in the monkey," Ultrasound Med. Biol., vol. 20, pp. 65-72, 1994.

[14] R. Baggs, D. P. Penney, C. Cox, S. Z. Child, C. H. Raeman, D. Dalecki, and E. L. Carstensen, "Thresholds for ultrasonically induced lung hemorrhage in neonatal swine," Ultrasound Med. Biol., vol. 22, pp. 119-128, 1996.

[15] D. Dalecki, S. Z. Child, C. H. Raeman, C. Cox, and E. L. Carstensen, "Ultrasonically induced lung hemorrhage in young swine," Ultrasound Med. Biol., vol. 23, pp. 777-781, 1997.

[16] C. L. Hartman, S. Z. Child, D. P. Penney, and E. L. Carstensen, "Ultrasonic heating of lung tissue," J. Acoust. Soc. Amer., vol. 91, pp. 513-516, 1992.

[17] W. D. O'Brien, Jr., L. A. Frizzell, R. M. Weigel, and J. F. Zachary, "Ultrasound-induced lung hemorrhage is not caused by inertial cavitation," J. Acoust. Soc. Amer., vol. 108, pp. 1290$1297,2000$.

[18] Mechanical bioeffects from diagnostic ultrasound: AIUM consensus statements, J. Ultrasound Med., vol. 19, pp. 67-168, 2000.

[19] American Institute of Ultrasound in Medicine, Standard for Real-Time Display of Thermal and Mechanical Acoustic Output Indices on Diagnostic Ultrasound Equipment, rev. 1. Rosslyn, VA: National Electrical Manufacturers Assoc. (NEMA Publ. UD 3), 1998.

[20] Center for Devices and Radiological Health, Use of Mechanical Index in Place of Spatial Peak, Pulse Average Intensity in Determining Substantial Equivalence. Rockville, MD: U.S. Food and Drug Administration, April 14, 1994.

[21] K. Raum and W. D. O'Brien, Jr., "Pulse-echo field distribution measurement technique of high-frequency ultrasound sources," IEEE Trans. Ultrason., Ferroelect., Freq. Contr., vol. 44, pp. 810-815, 1997.

[22] J. M. Sempsrott and W. D. O'Brien, Jr., "Experimental verification of acoustic saturation," Proc. IEEE Ultrason. Symp., 1999, pp. $1287-1290$.

[23] J. M. Sempsrott, Experimental evaluation of acoustic saturation, M.S. thesis, Dep. Elect. Comput. Eng., Univ. Illinois, Urbana, 2000.

[24] American Institute of Ultrasound in Medicine, Acoustic Output Measurement Standard for Diagnostic Ultrasound Equipment. rev. 2. Rosslyn, VA: National Electrical Manufacturers Association (NEMA Publ. UD 2), 1998.

[25] G. A. Teotico, R. J. Miller, L. A. Frizzell, J. F. Zachary, and W. D. O'Brien, Jr., "Attenuation coefficient estimates of mouse and rat chest wall," IEEE Trans. Ultrason., Ferroelect., Freq. Contr., vol. 48, no. 2, pp. 593-601, 2001.

[26] D. W. Hosmer and S. Lemeshow, Applied Logistic Regression. New York: Wiley, 1989.

[27] D. G. Simpson, R. J. Carroll, H. Zhou, and D. J. Guth, "Interval censoring and marginal analysis in ordinal regression," J. Agric. Biol. Environ. Statist., vol. 1, pp. 354-376, 1996.

[28] D. G. Simpson, CatReg [Online]. Available FTP: //www.stat.uiuc.edu/pub/faculty/simpson/catreg, 2001.

[29] R. D. Cook, "Detection of influential observations in linear regression," Technometrics, vol. 19, pp. 15-18, 1977.

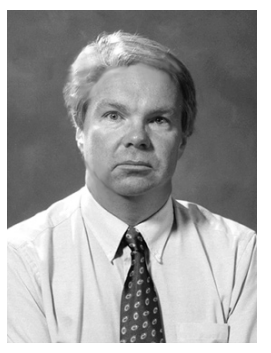

James F. Zachary received the B.S. Degree from Northern Illinois University, Dekalb in 1972 and D.V.M. and Ph.D. degrees in 1977 and 1983 respectively, from the University of Illinois, Urbana-Champaign.

From 1978, he has been at the University of Illinois, where he is a Professor of Pathology and a Bioengineering Faculty Member. His research interests involve ultrasound-tissue interaction and include biological effects, tissue characterization, bloodflow measurements, and acoustic microscopy. He has published more than 60 papers.

Dr. Zachary has served as Editor-in-Chief of Veterinary Pathology and is currently a co-editor of the textbook Thomson's Special Veterinary Pathology. He is a Diplomate of the American College of Veterinary Pathologists and a member of the American Institute of 
Ultrasound in Medicine (AIUM), the American Society for Investigative Pathology (ASIP-FASEB), and the Society for Neuroscience. He currently is a member of the AIUM Bioeffects Committee.

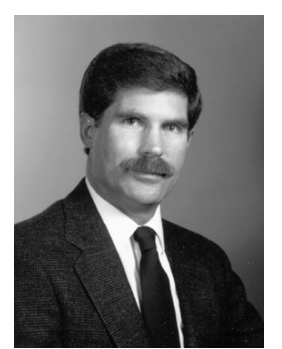

Leon A. Frizzell (S'71-M'74-SM'82) was born in West Stewartstown, NH, on September 12,1947 . He received the B.S. degree in physics from the University of New Hampshire, Durham, in 1969, and the M.S. and $\mathrm{Ph} . \mathrm{D}$. degrees in electrical engineering from the University of Rochester, Rochester, NY, in 1971 and 1976, respectively.

Since 1975, he has been in the Department of Electrical and Computer Engineering at the University of Illinois at Urbana-Champaign, where he is currently a professor of electrical and computer engineering and bioengineering. He was Acting Director of the Bioacoustics Research Laboratory within the Department of Electrical and Computer Engineering from August 1989 to August 1990 and served as Chair of the Bioengineering Faculty from August 1995 to December 1999. He was also a visiting research scientist at Yale University from August 1985 to August 1986. His research interest are in ultrasound and include tissue characterization, biological effects, hyperthermia, surgery, and bioengineering.

Dr. Frizzell is a Fellow of the American Institute of Ultrasound in Medicine, Fellow of the Acoustical Society of America, Fellow of the American Institute for Medical and Biological Engineering, and a member of Eta Kappa Nu and Sigma Xi.

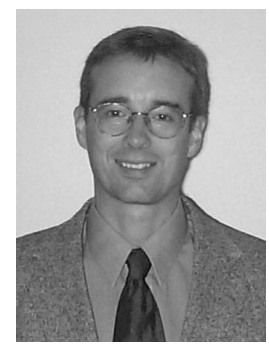

Douglas G. Simpson received the B.A. degree in 1980 from Carleton College and the M.S. and Ph.D. degrees in 1983 and 1985 from the University of North Carolina at Chapel Hill.

From 1985 he has been at the University of Illinois at Urbana-Champaign, where he is Professor and Chair of the Department of Statistics, former Director of the Illinois Statistics Office, and a member of the Faculty of the Interdisciplinary Environmental Toxicology Program. His research interests include computational statistics, environmental toxicology, chemometrics, generalized regression analysis, multivariate analysis and robust inference. He has published more than 35 papers.

Dr. Simpson is an Associate Editor of Biometrics, co-editor of Sankhya, a member of the editorial board of Chemometrics and Intelligent Laboratory Systems, and a former Associate Editor of the Journal of the American Statistical Association. He is a Fellow of the American Statistical Association (ASA) and the Institute of Mathematical Statistics (IMS). He has served as IMS Representative to the AMS/IMS/SIAM Joint Committee on Summer Research Conferences (1995-1997) and as a review panelist for the EPA/NSF Environmental Statistics program (2000). He was the 1997 Program Chair of the ASA Biometrics Section for the Spring Meetings of the ASA, IMS and Biometric Society, and the 1999 Program Chair for the ASA Section on Statistical Consulting.

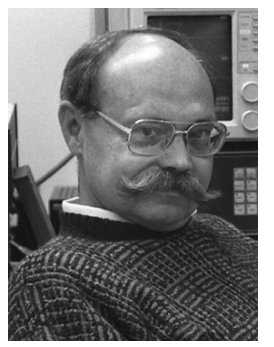

William D. O'Brien, Jr. (S'64, M'70, SM'79, F'89) received the B.S., M.S., and Ph.D. degrees in 1966, 1968, and 1970, from the University of Illinois, Urbana-Champaign.

From 1971 to 1975 he worked with the Bureau of Radiological Health (currently the Center for Devices and Radiological Health) of the U.S. Food and Drug Administration. Since 1975 , he has been at the University of Illinois, where he is a Professor of Electrical and Computer Engineering and of Bioengineering, College of Engineering; Professor of Bioengineering, College of Medicine; Professor of Nutritional Sciences, College of Agricultural, Consumer and Environmental Sciences; a Research Professor in the Beckman Institute for Advanced Science and Technology; and a Research Professor in the Coordinated Science Laboratory. He is the Director of the Bioacoustics Research Laboratory and is the Program Director of the NIH Radiation Biophysics and Bioengineering in Oncology Training Program. His research interests involve the many areas of ultrasound-tissue interaction, including spectroscopy, risk assessment, biological effects, tissue characterization, dosimetry, blood-flow measurements, acoustic microscopy and imaging for which he has published 215 papers.

Dr. O'Brien is Editor-in-Chief of the IEEE Transactions on Ultrasonics, Ferroelectrics, and Frequency Control. He is a Fellow of the Institute of Electrical and Electronics Engineers (IEEE), the Acoustical Society of America (ASA) and the American Institute of Ultrasound in Medicine (AIUM), and a Founding Fellow of the American Institute of Medical and Biological Engineering. He was recipient of the IEEE Centennial Medal (1984), the AIUM Presidential Recognition Awards (1985 and 1992), the AIUM/WFUMB Pioneer Award (1988), the IEEE Outstanding Student Branch Counselor Award for Region 4 (1989), the AIUM Joseph H. Holmes Basic Science Pioneer Award (1993), and the IEEE Ultrasonics, Ferroelectrics, and Frequency Control Society Distinguished Lecturer (1997-1998). He received the IEEE Ultrasonics, Ferroelectrics, and Frequency Control Society's Achievement Award for 1998, and the IEEE Millennium Medal in 2000. He has served as Co-Chair of the 1981 IEEE Ultrasonic Symposium, and General Chair of the 1988 IEEE Ultrasonics Symposium, and is Co-Chair of both the 2001 and 2003 IEEE Ultrasonics Symposia. He has been Secretary-Treasurer (1972-1980), Vice President (1981), and President (1982-1983) of the IEEE Sonics and Ultrasonics Group (currently the IEEE Ultrasonics, Ferroelectrics, and Frequency Control Society). He has been Treasurer (1982-1985), President-Elect (1986-1988) and President (1988-1991) of the American Institute of Ultrasound in Medicine. He has served on the Board of Directors (1988-1993) of the American Registry of Diagnostic Medical Sonographers, and has been Treasurer (1991-1994) of the World Federation for Ultrasound in Medicine and Biology. 